\title{
Porphyric Neuropathy: An Ultrastructural and Quantitative Case Study
}

\author{
P.S. THORNER, J.M. BILBAO, \\ A.A.F. SIMA and \\ S. BRIGGS
}

\begin{abstract}
SUMMARY: We report a case of acute neuropathy in a 46 year old female with porphyria variegata. Histologic, electron microscopic, and quantitative examinations of peripheral nerves were performed at onset of the neuropathy and at autopsy. The results revealed severe qualitative and quantitative changes in myelinated and unmyelinated fibers showing features indicative of an axonopathy with a distribution in keeping with a dying-back phenomenon.
\end{abstract}

RÉSUMÉ: Nous rapportons un cas fatal de neuropathie aigue chez une femme de 46 ans avec porphyrie variegata. Des examens histologiques, de microscopie électronique et quantitatifs des nerfs périphériques furent obtenus au début de la neuropathie et à lautopsie. On montra ainsi des changements de structure importants et quantitatifs au niveau des fibres myélinisées et non myélinisées. Ces changements indiquent une axonopathie compatible avec le phénomène du "dying-back".
From St. Michael's Hospital, Toronto General Hospital and The University of Toronto, Canada

Requests for reprints to Dr. A.A.F. Sima, Division of Neuropathology, Department of Pathology, Banting Institute, 100 College Street, Toronto, Ontario, Canada M5G 1 L5.

\section{INTRODUCTION}

The hepatic porphyrias are characterized by acute attacks of neurological dysfunction which often result in the patient's death (Goldberg, 1959; Eales \& Linder, 1962; Eales, 1963; Bloomer, 1976). The clinical presentation includes colicky abdominal pain, neuropsychiatric disorders, and peripheral neuropathy. After a single attack the neuropathy may be reversible whereas repeated or prolonged attacks cause irreversible peripheral nerve damage (Berg, 1945; Flügel and Kruschky, 1977; Wochnik-Dyjas, et al, 1978).

The time course of the neuropathy may be rapidly progressive, reaching flaccid paralysis in days (Goldberg, 1959), or proceed at a slower pace evolving over months. There are conflicting reports regarding the basic pathology of porphyric neuropathy. Early authors (Denny-Brown \& Sciarra, 1945: Gibson \& Goldberg, 1956; Campbell, 1963), supported segmental demyelination as the primary process whereas recent investigators like Cavanagh and co-workers (Cavanagh \& Mellick, 1965; Cavanagh \& Ridley, 1967; Schoental \& Cavanagh, 1977), and others (Sweeney, et al, 1970; Tschudy, et al, 1975), suggest that axonal degeneration is the basic structural change in porphyric neuropathy.

This report describes the qualitative and quantitative changes in a sural nerve biopsy and in post mortem material obtained from the tibial nerve, ventral and dorsal sacral roots.

\section{CASE HISTORY}

The patient was a 46 year old Caucasian woman with a past history of depression $(1973,1977)$ and abdominal pain with diarrhea in 1978. She was on no medica- tions and denied any photosensitivity. In August 1979, she developed protracted vomiting, which was attributed to cholelithiasis, and a cholecystectomy was performed. Post-operatively the vomiting continued and over the next three weeks, the patient's neurological status deteriorated. She remained alert and oriented but developed a flat affect and recent memory loss. She suffered overflow incontinence and constipation. Cranial nerves were normal. She developed an ascending motor weakness with $4 / 5$ power in all muscle groups of the upper extremities and 3/5 power in all groups of the lower extremities. Tendon reflexes were absent at the knees, ankles and wrists. The biceps tendon reflexes were $1+$. Decreased sensation to light touch only was noted in both hands and both feet.

A diagnosis of Guillain-Barré syndrome was considered and electrophysiologic examinations were performed by Dr. Henry Berry on September 20, 1979. The conduction velocity in the left lateral popliteal nerve was $38.0 \mathrm{~m} / \mathrm{sec}$, the lower limit of normal being $40 \mathrm{~m} / \mathrm{sec}$. The conduction velocities of the left superfical peroneal nerve and the left sural nerve were absent. Testing of the right frontalis muscle revealed fibrillation potentials and no motor units under voluntary control. The left tibialis anterior muscle showed no fibrillation or fasciculation and a few motor units under voluntary control. The upper limbs could not be examined.

A sural nerve biopsy was performed on September 26, 1979.

Four weeks later further neurological deterioration had occurred. The patient was disoriented to time and place, unable to perform calculations, and demonstrated loss of remote memory, judgement and insight. Cranial nerves were normal. Her muscle bulk had greatly decreased and power testing revealed $1 / 5$ power in all muscle groups of the legs and $2 / 5$ power in the arms.

A stocking type loss to pin-prick and touch was noted extending to above the knees. 
TABLE 1

Results of Laboratory Investigations

BLOOD URINE STOOL

$\begin{array}{llll}\delta \text {-ALA } & 0.69 \mathrm{mg} \%(\mathrm{~N}<0.30) & - & - \\ \text { PORPHOBILINOGEN } & \text { POSITIVE }(\mathrm{N}=\text { negative }) & \text { POSTIVE }(\mathrm{N}=\text { negative }) & - \\ \text { UROPORPHYRINS } & 250 \mathrm{mg} / \mathrm{d}(\mathrm{N}<30) & 24 \mathrm{mg} / \text { day }(\mathrm{N}=0) & 143 \mathrm{mg} \%(\mathrm{~N}<100) \\ \text { COPROPORPHYRINS } & 803 \mu \mathrm{g} / \mathrm{d}(\mathrm{N}=75-275) & 265 \mathrm{mg} / \text { day }(\mathrm{N}=50-250 \mu \mathrm{g} / \text { day }) & 1384 \mathrm{mg} \%(\mathrm{~N}<700) \\ \text { PROTOPORPHYRINS } & - & - & 2050 \mathrm{mg} \%(\mathrm{~N}<1500)\end{array}$

CSF examination, CT scan of the head and a myelogram were all normal. A diagnosis of porphyria variegata was considered and confirmed by laboratory studies (Table 1).

Three distant female relatives had experienced symptoms suggestive of porphyria but there was no biochemical confirmation of the diagnosis.

During her hospital course the patient suffered three bouts of aspiration pneumonia which were treated with broad spectrum antibiotics. In late November she developed increasing agitation and systemic candidiasis. She died on November $25,1979$.

At autopsy systemic candidiasis involving the kidneys, myocardium, brain and the spinal cord was noted. Bilateral aspiration pneumonia was seen. The relevant neuropathology is described in detail.

\section{MATERIAL AND METHODS}

The sural nerve obtained by biopsy, and ventral and dorsal $S_{1}$ roots and tibial nerve dissected at post-mortem examination, 7 hours after death, were fixed in cacodylate buffered $2 \%$ glutaraldehyde, post-fixed in Millonigbuffered $1 \%$ osmium tetroxide, dehydrated and embedded in Epon-Araldite. Cross and longitudinal 1 micron thick sections were stained with toluidine blue for light microscopy. Ultra-thin sections were stained with uranyl acetate and lead citrate and examined under the electron microscope. In addition, spinal root ganglia, spinal cord and skeletal muscle were fixed in neutral formaldehyde and examined under the light microscope.

Caliber-spectra and fiber densities of myelinated fibers were calculated from photomicrographs at a final magnification of 1000 . In each nerve all myelinated fibers of one randomly chosen fascicle were counted. Caliberspectra and fiber densities of unmyelinated fibers were calculated from unselected electron micrographs with a final magnification of 15,000 . The axon-myelin ratios were examined in randomly chosen fibers, which showed no axon or myelin destruction, at a final magnification of 15,000 , using the methods of Robertson and Sima (1980). Linear regressions for the relationship between the natural log. of axis cylinder area and myelin thickness as measured by the number of lamellae were calculated (cf. Dyck et al, 1981).

Control nerves were obtained 8 hours post-mortem from a 52 year old woman who died without neurological disease. The morphometric measurements were performed on a HewlettPackard 9874A Digitizer interfaced with a Hewlett-Packard 9825A Computer.

\section{RESULTS}

\section{Structural Changes:}

Sural Nerve Biopsy: Light microscopic examination of thick sections revealed a marked reduction in the number of large myelinated fibers (Fig. 1). Electron microscopy showed extensive axonal degenerative changes consisting of dissolution of the axoplasmic organelles, granular degeneration of the axoplasm and ingrowth of the inner Schwann cell lip (Fig. 2), sometimes forming honeycomb structures at the axon-Schwann cell interface. Many of the affected fibers showed well preserved myelin sheaths. Other fibers revealed a later stage of axonal degeneration, namely complete disintegration of the axon (Fig. 3), collapse and fragmentation of the myelin and the development of denervated Schwann cells (Fig. 3). Some of the smaller myelinated fibers were uninvolved. Unmyelinated fibers showed axonal fragmentation and retraction of Schwann cell cytoplasm leaving axons directly apposed to basement lamina (Fig. 4). Large unmyelinated fibers frequently demonstrated a separation of neurofilaments and tubules with the neurofilaments in a central position (Fig. 5).

Tibial Nerve: Light microscopic examination of thick sections showed depletion of large myelinated fibers and a large number of free foamy macrophages in the endoneurium (Fig. 6). In the electron microscope smallsized myelinated fibers showed marked axonal atrophy. Others contained accumulation of membranous lipid structures in the axons. Clusters of regenerating units consisting of axons with thin myelin sheaths and duplicated basement membranes were occasionally found. The changes in the unmyelinated fibers were similar to those described in the sural nerve. In particular, there was a large number of single axon-Schwann cell units with pronounced Schwann cell banding. Occasionally unmyelinated fibers contained dense accumulations of misdirected $10 \mathrm{~nm}$ neurofilaments which caused axonal distention (Fig. 7).

Ventral and Dorsal roots: Changes in the spinal roots were less severe than in the tibial and sural nerves. Many myelinated fibers appeared normal, whereas others showed complex mem- 


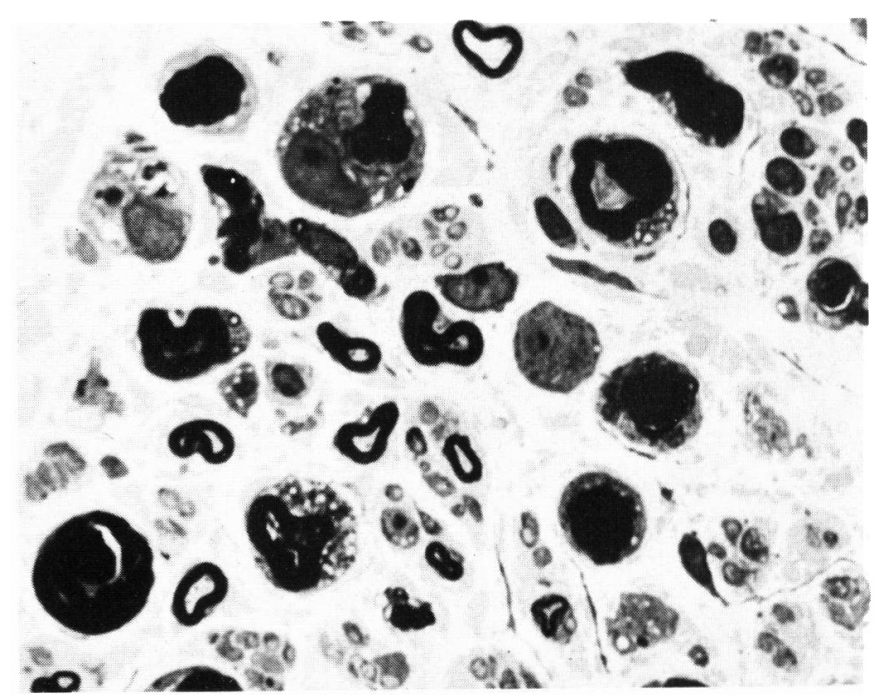

Figure 1 -Toluidine-blue stained plastic section of the sural nerve showing loss of myelinated fibers and denervated Schwann cell units some of which contain myelin debris. Mag. $750 \mathrm{x}$.

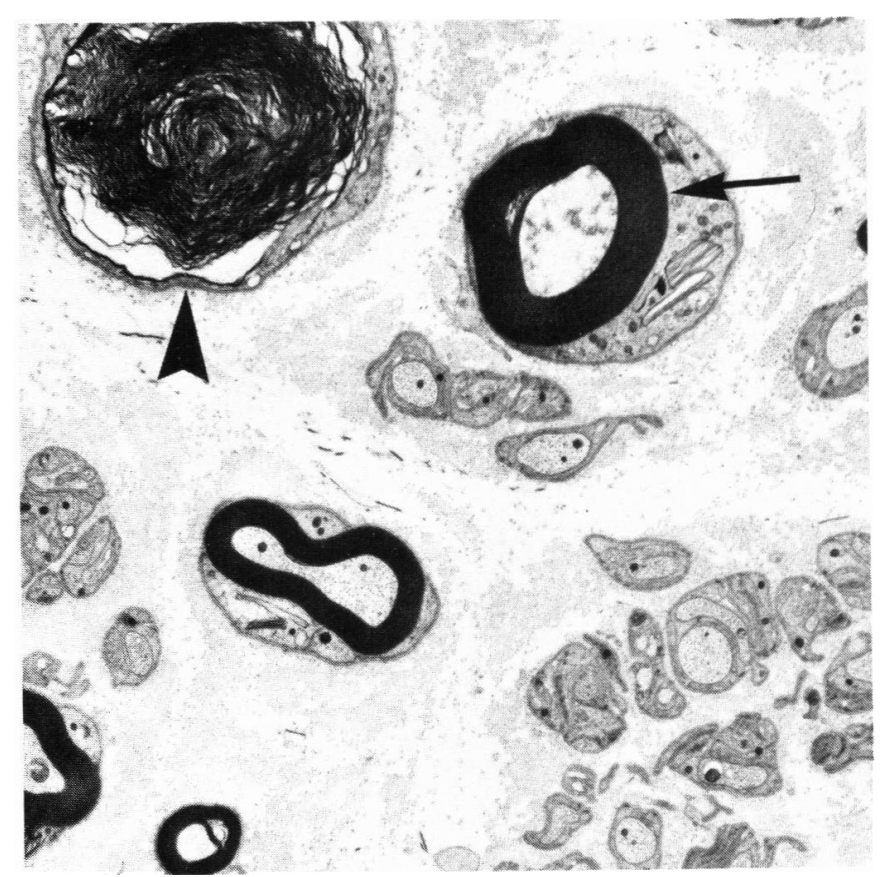

Figure 3-Sural nerve showing myelinated fiber with complete disintegration of its axon (arrow). Another fiber (arrow-head) shows denervation and delamination of the myelin-sheath. Mag. $3630 \mathrm{x}$.

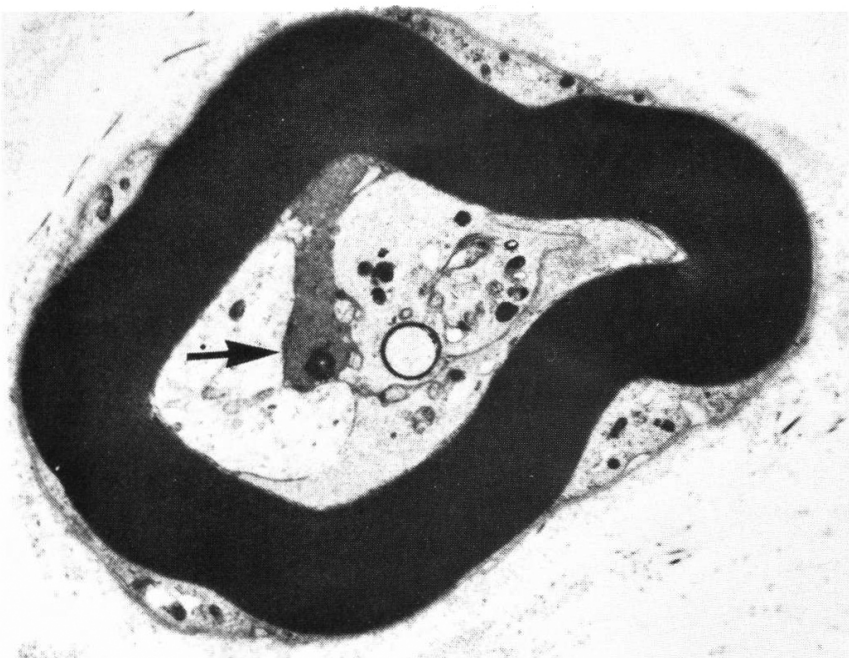

Figure 2-Myelinated fiber from the sural nerve showing ingrowth of the adaxonal Schwann cell cytoplasm into the axon (arrow). Note granular degeneration of the axonplasm. Mag. 7480 .

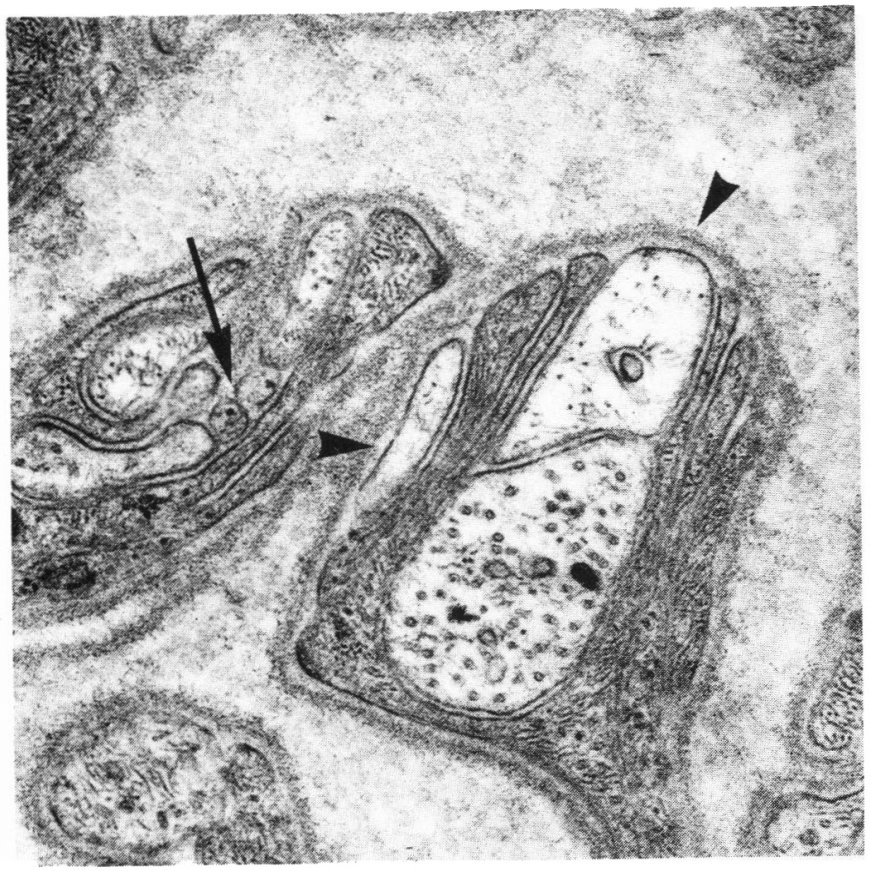

Figure 4-Unmyelinated fibers of the sural nerve. One fiber shows fragmentation of the axoplasm (arrow). Other fibers are partly denuded from the ensheathing Schwann cell (arrow-heads) Mag. $33150 \mathrm{x}$. branous Schwann cell processes invading the axons, and accumulation of organelle debris in the axons. Axonal atrophy was marked, particularly in large sized fibers. In addition, the ventral root contained numerous regenerating units. (Fig. 8).

\section{QUANTITATIVE CHANGES}

\section{Caliber Spectra:}

Myelinated fibers: The tibial and the sural nerves and the unifascicular spinal roots showed marked shifts of their caliber-spectra toward thinner di- ameters (Fig. 9). These shifts were more marked in the tibial and sural nerves and less marked in the ventral and dorsal roots. The fiber densities were decreased in the sural and tibial nerves, whereas they were increased in the spinal roots, particularly in the 


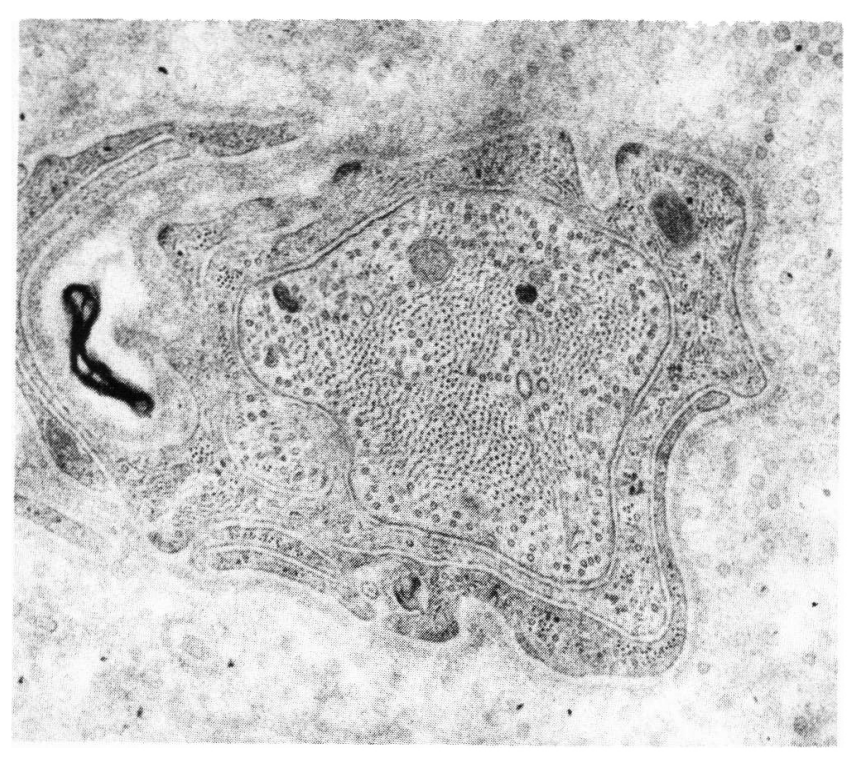

Figure 5-Unmyelinated fiber of the sural nerve showing central displacement of neurofilaments and peripheral localization of neurotubules. Mag. 27950 x.

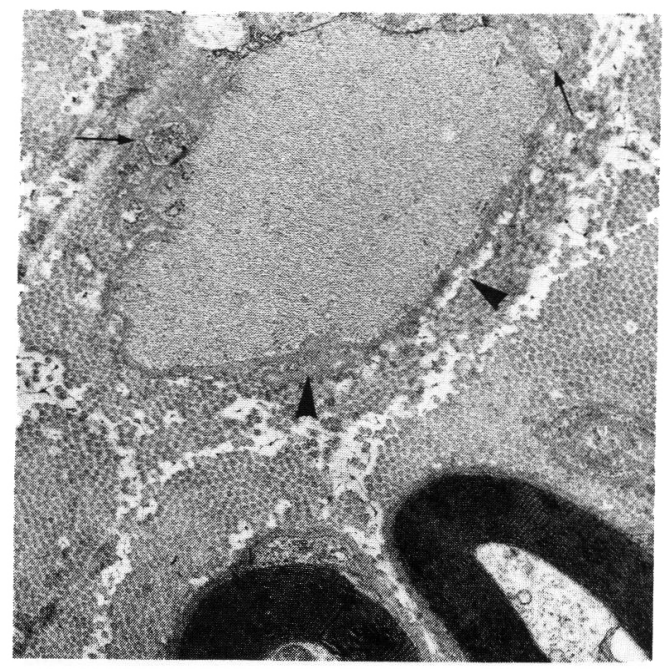

Figure 7-Tibial nerve showing enlarged unmyelinated axon packed with neurofilaments (arrow-heads). The diameter measured 3.5 microns. The parent Schwann cell contains in addition normal-sized axons (arrows). Mag. $14300 \mathrm{x}$.

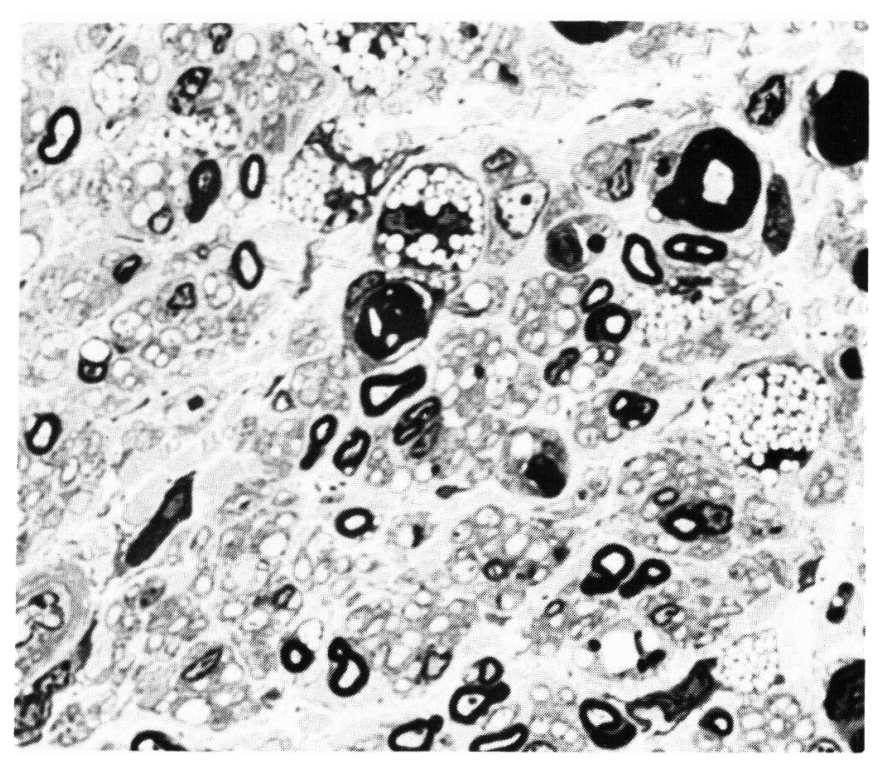

Figure 6-Toluidine-blue stained plastic section of the tibial nerve. There is depletion of large myelinated fibers and several free foamy macrophages. Mag. $750 \mathrm{x}$.

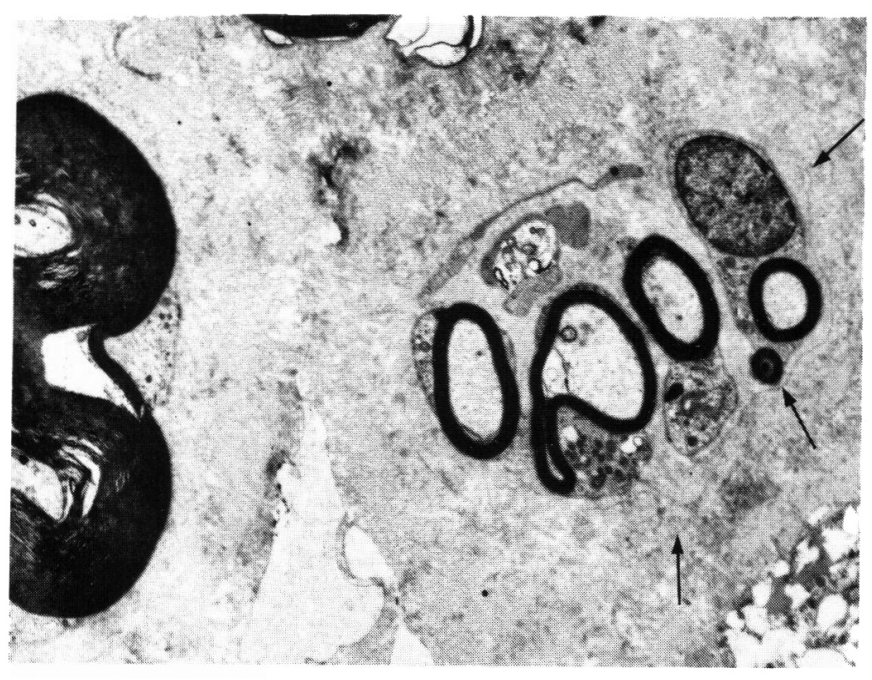

Figure 8-Ventral root showing a cluster of small relatively thinly myelinated fibers. Each individual Schwann cell is surrounded by a basement membrane. In addition a redundant basement membrane can be seen surrounding the whole group of fibers (arrows). Mag. 5325. ventral root. The total fiber number showed an absolute decrease in the dorsal root and a slight increase in the ventral root (Table 2).

Unmyelinated fibers: Unmyelinated fiber sizes were shifted toward thinner diameters in both the tibial and the sural nerves. The tibial nerve showed a small population (approximately $2.5 \%$ ) of unmyelinated fibers with larger diameters than were found in the control nerve (Fig. 9). These fibers represent in part those exhibiting axonal swelling due to dense accumulations of neurofilaments. The densities of unmyelinated fibers per area unit was markedly increased in the tibial nerve and marginally increased in the sural nerve (Table 2).
Axon-myelin ratio: Both the ventral root and the tibial nerve showed significantly decreased ratios between the axonal area and the number of myelin lamellae (Fig. 10), indicating severe axonal atrophy.

Light microscopic examination: Dorsal root ganglia showed mild loss of neurons. The ventral horns of the 
TABLE 2

Numeric data of morphometric examinations depicting number of fibers counted and fiber density per area unit.

$$
P=\text { Patient }
$$

$C=$ Control

\section{MYELINATED FIBERS}

\section{FIBER NUMBER/FASCICLE}

VENTRAL ROOT
DORSAL ROOT
TIBIAL NERVE
SURAL NERVE

$\begin{array}{ll}\text { TIBIAL NERVE } & \mathbf{P} \\ & \mathrm{C}\end{array}$

SURAL NERVE P C

UNMYELINATED FIBERS

\section{FIBER NUMBER}

549

358

333

367

FIBER DENSITY (FIBERS/MM ${ }^{2}$ )

$$
\begin{array}{r}
14,786 \\
4,641 \\
9,829 \\
8,776 \\
5,205 \\
6,425 \\
2,133 \\
6,146
\end{array}
$$

FIBER DENSITY (FIBERS/MM ${ }^{2}$ )

115,336

40,498

69,957

61,319 spinal cord showed moderate neuronal loss and chromatolysis of preserved neurons. In skeletal muscle, grouped fiber atrophy was seen.

\section{DISCUSSION}

The present study has demonstrated severe qualitative and quantitative changes in myelinated and unmyelinated nerve fibers in a patient with porphyric neuropathy. The sural nerve biopsy obtained during the early course of the disease revealed acute degenerative changes such as axonal sequestration by the inner Schwann cell lip and granular degeneration of the axoplasm in myelinated axons. These changes were accompanied by only minor structural changes of the Schwann cell and myelin sheath and are therefore indicative of a primary axonal involvement. More severe changes consisted of complete axonal disintegration and Wallerian degeneration. The caliber-spectrum analysis demonstrated that large myelinated fibers were especially involved in the disease process. In contrast, Anzil and Dozic (1978), found small-sized fibers to be mainly involved in porphyric neuropathy.

The examination of the tibial nerve 9 weeks later revealed less acute degenerative changes. There was marked axonal atrophy, (objectively demonstrated by the axon-myelin ratio), numerous free foamy macrophages and a large number of regenerating units, indicating a more longstanding process. In the spinal roots, the axonal degenerative and atrophic changes were less obvious, although the ventral root revealed marked regenerative activity. This was also reflected by 1) a slight absolute increase in the number of myelinated fibers, presumably representing remyelination of sprouting fibers, and 2) a significantly increased fiber density of the ventral root, since more small remyelinating fibers can be harbored per area unit. The presence of oc- casional degenerating neurons in the spinal ganglia and the ventral horns suggests that the disease process had progressed to the cell somata.

The qualitative changes and the topographic difference in severity of quantitative changes in the peripheral nerves is suggestive of a primary axonopathy of dying-back type. (Schoental \& Cavanagh, 1977; Spencer \& Schaumburg, 1977; Cavanagh, 1979; Sima, et al, 1981). Early investigators (Denny-Brown \& Scirra, 1945; Gibson \& Goldberg, 1956; Campbell, 1963) have suggested that demyelination is the primary disease process in porphyric neuropathy. In the present study demyelination was certainly a prominent pathologic feature, although this must be interpreted as being secondary to axonal degeneration, based on the results of more recent investigative techniques used here such as quantitative morphology and ultrastructure.

One might however argue that the axonal atrophy could possibly be due to disuse during the patient's hospitalization (Eisen et al, 1973). However this seems unlikely because of the sudden onset of the patient's neuromuscular complaints and the rapid progression to a flaccid areflexic quadriplegia.

The structural changes reported in the present case show similarities with those recently reported in mice after the injection of a synthetic porphyrin, tetraphenylporphinesulfonate (Sima, et al, 1981). In this experimental model, peripheral motor nerves exhibited progressive axonal degenerative changes with secondary demyelination, evolving from the motor nerve terminals (Felix \& Sima, 1981), to the ventral roots (Sima, et al, 1981).

Qualitative and quantitative changes of unmyelinated fibers in porphyric neuropathy have not previously been reported, although the clinical picture of acute porphyria suggests that this fiber population is most likely involved in the disease process (Tschudy, et al, 1975; Becker \& Kramer, 1977). In the present case, unmyelinated fibers showed axonal degeneration with sequestration of axonal material and marked atrophy. Similar structural changes of unmyelinated fibers have 
previously been reported in experimental diabetes (Sima \& Robertson, 1979; Sima, 1980). Many unmyelinated fibers were found to be denuded from the ensheathing Schwann cells, a finding that has been reported in painful diabetic neuropathy (Brown, et al, 1976), and in different models of experimental diabetic neuropathy (Sima \& Robertson, 1979; Sima, 1980). An interesting observation was a small population of unmyelinated fibers that exhibited axonal swelling due to dense accumulations of neurofilaments. This finding is similar to what is encountered in myelinated fibers in the experimental model referred to previously (Sima, et al, 1981). This observation may indicate development of porphyric neuropathy (Schoental \& Cavanagh, 1977; Cavanagh, 1979; Felix \& Sima, 1981; Sima, et al, 1981).

Although the mechanism(s) responsible for porphyric neuropathy is (are) poorly understood, it is generally felt that the precursors to porphyrins, delta-ALA and/or PBG are responsible for the neuropathy (Kramer, et al, 1973; Shanley, et al, 1975; Brodie, et al, 1976; Sima, et al, 1981), since these substances are elevated only in those porphyrias which show neurological manifestations. It has been suggested that these substances may inhibit enzymes and cofactors (Cavanagh \& that disturbed axonal transport could be of pathogenetic significance in the

\section{MYELINATED FIBERS}
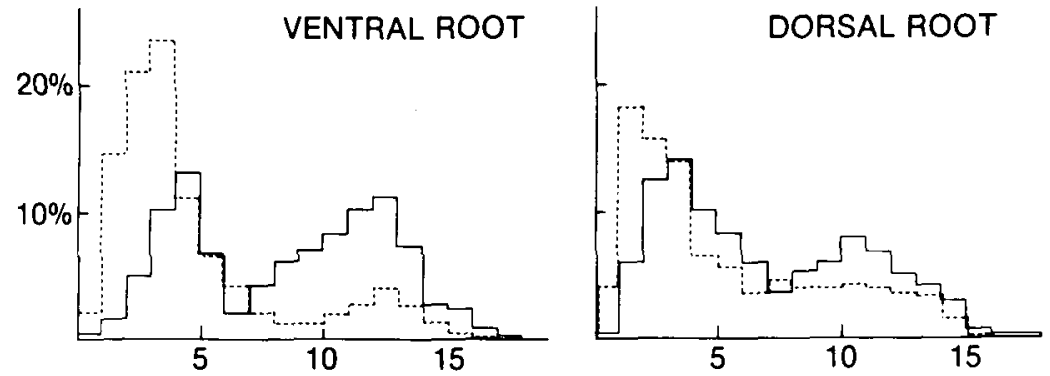

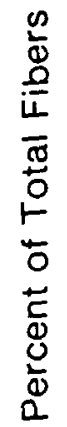
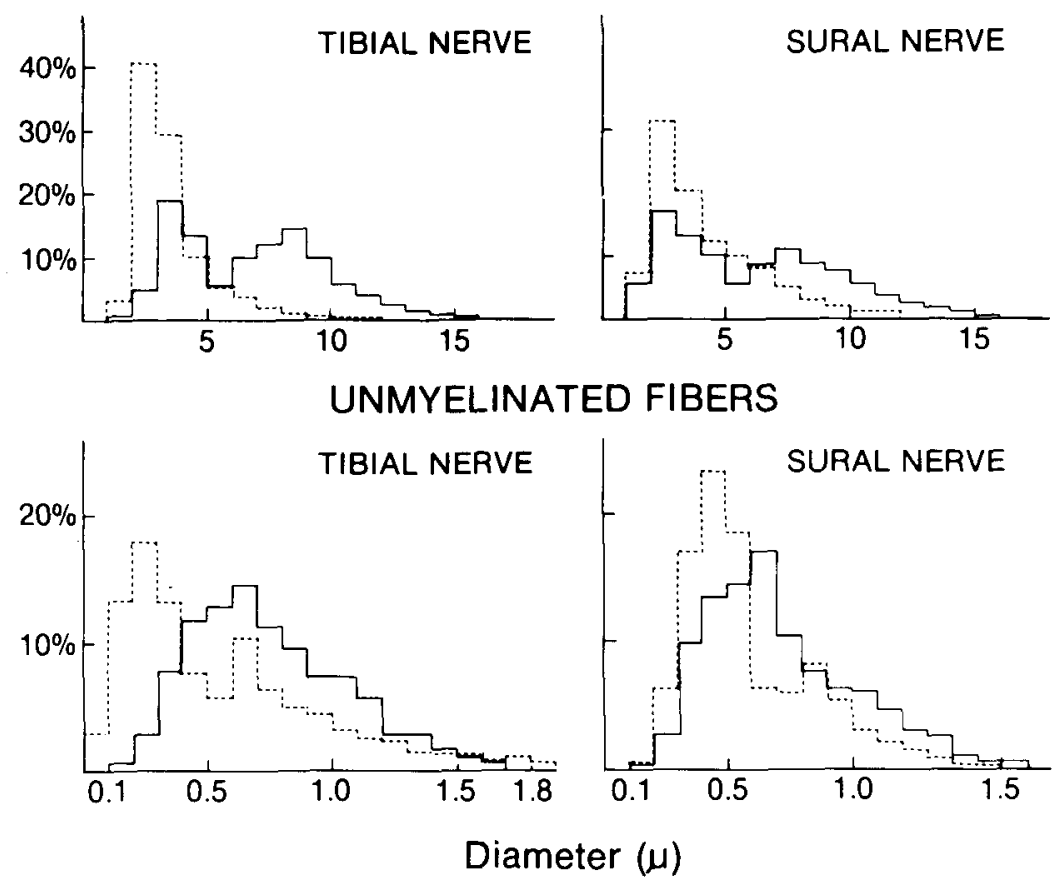

Figure 9-Caliber-spectra of myelinated and unmyelinated fibers. Patient $=$ dotted bars. Control $=$ solid bars.

\section{AXON-MYELIN RATIOS}

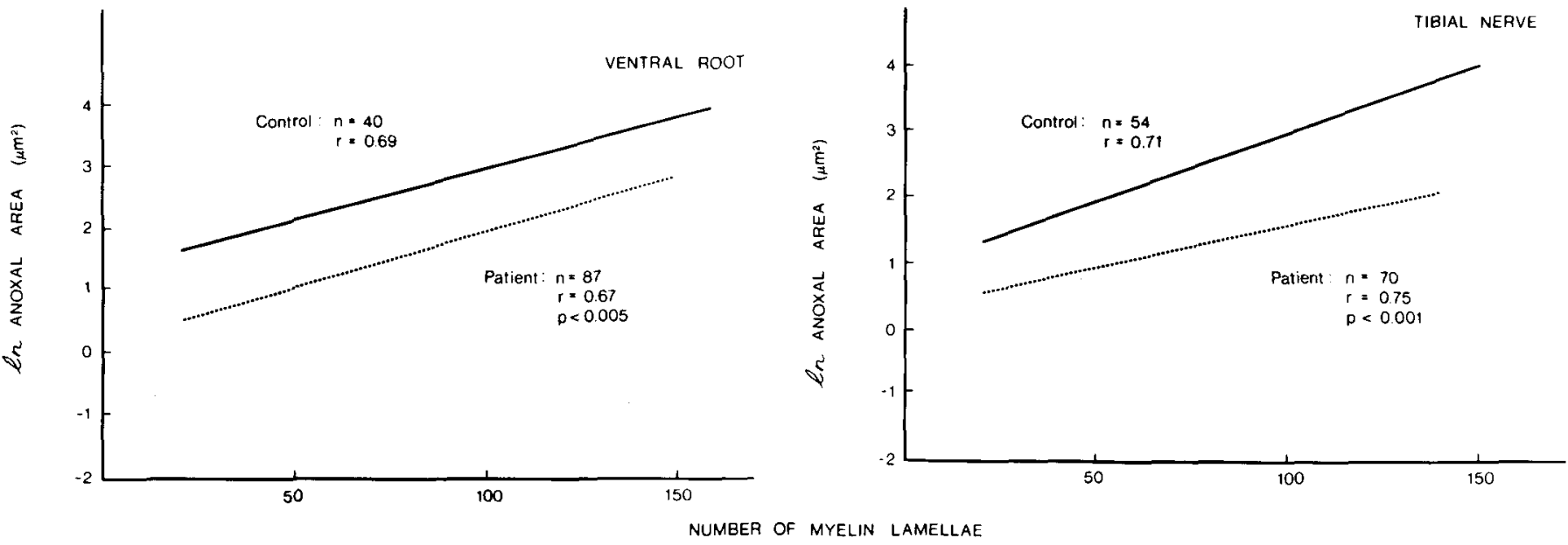

Figure 10 - Anon-myelin ratios in ventral root and tibial nerve. Patient $=$ dotted lines. Control = solid lines. Note markedly decreased ratios in the patient. 
Ridley, 1967; Schoental \& Cavanagh, 1977; Wochnik-Dyjas, et al, 1978; Cavanagh, 1979; Sima, et al, 1981), essential for the functional and structural integrity of the axon. In porphyria variegata a defect in ferrochelatase gives it the characteristic biochemical profile of elevated porphyrins and secondary elevation of delta-ALA and PBG (Brodie, et al, 1976; Becker and Kramer, 1977; Becker, et al, 1977).

In summary, the present study has demonstrated an axonal neuropathy affecting distal nerves more severely than proximal ones in a patient with porphyria variegata. Furthermore, severe structural and quantitative changes of unmyelinated fibers have been demonstrated for the first time in porphyric neuropathy.

\section{ACKNOWLEDGEMENTS}

The authors want to thank Ms Ann Catherine Lorusso and Mrs. Kazuko Hay for skillful technical assistance. This investigation was supported in part by grants from the Canadian Medical Research Council (MA-7117) and the Canadian Diabetic Association.

\section{REFERENCES}

ANZIL, A.P. \& DOZIC, S., (1978). Peripheral nerve changes in porphyric neuropathy: Findings in a sural nerve biopsy. Acta Neuropath. (Berl.) 42: 121-126.

BECKER, D.M., VILJOEN, J.D., \& KATZ, J., et al. (1977). Reduced ferrochelatase activity: A defect common to porphyria variegata and protoporphyria. Br. J. Hematol 36: 17-79.

BECKER, D.M., \& KRAMER, S., (1979). The neurological manifestations of porphyria: A review. Medicine 56: 411-423.

BERG, M., (1945). Acute porphyria. Clinical and pathological observations. Arch Intern Med. 76: 335-340.

BLOOMER, J.R., (1976). The hepatic porphyrias. Gastroenterology 71: 698-700.

BRODIE, M.J., THOMPSON, G.G. \& MOORE, M.R., et al: (1976). The enzyme abnormalities of the hepatic porphyrias. Gut 17: 823 .
BROWN, M.J., MARTIN, J.R., \& ASBURY, A.K.: (1976). Painful diabetic neuropathy. A morphometric study. Arch Neurol 33: 164171.

CAMPBELL, J.A.H., (1963). The pathology of South African genetic porphyria. S. Afr J. Lab Clin Med. 9: 197-203.

CAVANAGH, J.B., (1979). The "Dying Back" process. A common denominator in many naturally occurring and toxic neuropathies. Arch Pathol Lab Med 103: 659-664.

CAVANAGH, J.B., \& MELLICK, R.S., (1965). On the nature of the peripheral nerve lesions associated with acute intermittent porphyria. J Neurol Neurosurg Psychiat 28: 320-327.

CAVANAGH, J.B., \& RIDLEY, A.R., (1967). The nature of the neuropathy complicating acute intermittent porphyria. Lancet 2: 10231024.

DENNY-BROWN, D., \& SCIARRA, D., (1945). Changes in the nervous system in acute porphyria. Brain 68 : 1-16.

DYCK, P.J., LAIS, A.L., KARNES, J.L., SPARKS, M., HUNDER, H., LOW, P.A., \& WINDEBANK, A.J., (1981). Permanent axotomy, a model of axonal atrophy and secondary segmental demyelination and remyelination. Ann. Neurol. 9: 575-589.

EALES, L., \& LINDER, G.C., (1962). Porphyria - the acute attack. An analysis of 80 cases. S Afr Med J. 36: 284-292.

EALES, L., (1963). Porphyria as seen in Cape Town. A survey of 250 patients and some recent studies. S. Afr J Lab Clin Med 9: 151161.

EISEN, A., CARPENTER, S., KARPATI, G., BELLAVANCE, A., (1973). Effect of muscle hyper- and hypoactivity upon fiber diameter of intact and regenerating nerve. $J$ Neurol Sci 20: 457-469.

FELIX, A.I., \& SIMA, A.A.F., (1981). The effect of tetraphenylporphinesulfonate (TPPS) on muscle end-plate in mice. An ultrastructural and quantitative study. Submitted to Acta Neuropath. (Berl).

FLÚGEL, K.A., \& KRUSCHKY, K.F., (1977), Electromyogram and nerve conduction in patients with acute intermittent porphyria. J Neurol 214: 267-270.

GIBSON, J.B., \& GOLDBERG, A., (1956). The neuropathology of acute porphyria. J Path Bact 71: 495-508
GOLDBERG, A., (1959). Acute intermittent porphyria. Quart J Med 28: 183-209.

KRAMER, S., BECKER, D., \& VILJOEN, D., (1973). Significance of the porphyrin precursors, delta-ALA and porphobilinogen in the acute attacks of porphyria. S Afr Med J 47: 1735-1738.

ROBERTSON, D.M., \& SIMA, A.A.F., (1980). Diabetic neuropathy in the mutant mouse (C57BL/Ks [db/db]). A morphometric study. Diabetes 29: 60-67.

SCHOENTAL, R., \& CAVANAGH, J.B., (1977). Mechanisms involved in the "dyingback" process - a hypothesis implicating coenzymes. Neuropath Appl Neurobiol 3: 145-157.

SHANLEY, B.C., NEETHING, A.C., \& PERRY, V.A., et al (1975). Neurochemical aspects of porphyria. Studies on possible aspects of delta-ALA. S Afr Med J 49: 576580.

SPENCER, P.S., \& SCHAUMBURG, M.D., (1977). Central-peripheral distal axonopathy - The pathology of dying-back polyneuropathies. Progress in Neuropath 3: 253-295.

SIMA, A.A.F., (1980). Peripheral neuropathy in the spontaneously diabetic BB-Wistar rat. An ultrastructural study. Acta Neuopath (Berl) 51: 223-227.

SIMA, A.A.F., KENNEDY, J.C., BLAKESLEE, D., \& ROBERTSON, D.M., (1981). Experimental porphyric neuropathy. A preliminary report. Can J Neurol Sci 8: $105-$ 114.

SIMA, A.A.F., \& ROBERTSON, D.M., (1979). Peripheral neuropathy in the diabetic mutant mouse (C57 BL/Ks [db/db]). An ultrastructural study. Lab Invest 40: 627632.

SWEENEY, V.P., PATHAK, M.A., \& ASBURY, A.K., (1970). Acute intermittent porphyria. Increased delta-ALA synthetase activity during an acute attack. Brain 93: 369-380.

TSCHUDY, D.P., VALSAMIS, M., and MAGNUSSEN, C.R., (1975). Acute intermittent porphyria: Clinical and selected research aspects. Ann Int Med 83: 851-864.

WOCHNIK-DYJAS, D., NIEWIADAMSKA, M., \& KOSTRZEWSKA, E., (1978). Porphyric polyneuropathy and its pathogenesis in the light of electrophysiological investigations. J Neurol Scii 35: 243-256. 